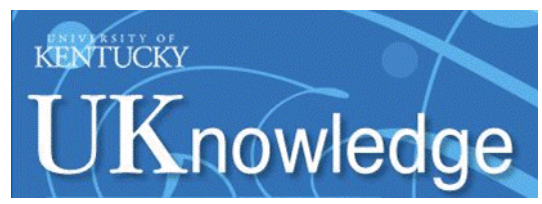

University of Kentucky

UKnowledge

$9-22-2016$

\title{
Glycemic Variability Predicts Inflammation in Adolescents with Type 1 Diabetes
}

\author{
Robert P. Hoffman \\ The Ohio State University \\ Amanda S. Dye \\ West Virginia University \\ Hong Huang \\ University of Kentucky, hong.huang@uky.edu \\ John A. Bauer \\ University of Kentucky, john.bauer@uky.edu
}

Follow this and additional works at: https://uknowledge.uky.edu/pediatrics_facpub

Part of the Cardiovascular Diseases Commons, Endocrinology, Diabetes, and Metabolism Commons, and the Pediatrics Commons

Right click to open a feedback form in a new tab to let us know how this document benefits you.

\section{Repository Citation}

Hoffman, Robert P.; Dye, Amanda S.; Huang, Hong; and Bauer, John A., "Glycemic Variability Predicts Inflammation in Adolescents with Type 1 Diabetes" (2016). Pediatrics Faculty Publications. 222.

https://uknowledge.uky.edu/pediatrics_facpub/222

This Article is brought to you for free and open access by the Pediatrics at UKnowledge. It has been accepted for inclusion in Pediatrics Faculty Publications by an authorized administrator of UKnowledge. For more information, please contact UKnowledge@lsv.uky.edu. 


\section{Glycemic Variability Predicts Inflammation in Adolescents with Type 1 Diabetes}

Digital Object Identifier (DOI)

https://doi.org/10.1515/jpem-2016-0139

\section{Notes/Citation Information}

Published in Journal of Pediatric Endocrinology and Metabolism, v. 29, issue 10, p. 1129-1133.

@2016 Walter de Gruyter GmbH, Berlin/Boston.

The copyright holder has granted the permission for posting the article here. 


\section{Robert P. Hoffman*, Amanda S. Dye, Hong Huang and John A. Bauer Glycemic variability predicts inflammation in adolescents with type 1 diabetes}

DOI 10.1515/jpem-2016-0139

Received April 12, 2016; accepted August 1, 2016; previously published online September 22, 2016

\section{Abstract}

Background: Adolescents with type 1 diabetes (T1D) have increased risk of cardiovascular disease as well as elevations in biomarkers of systemic inflammation, plasma protein oxidation and vascular endothelial injury. It is unclear whether hyperglycemia itself, or variations in blood glucose are predictors of these abnormalities.

Methods: This study was designed to determine the relationship of inflammatory (C-reactive protein, CRP), oxidative (total anti-oxidative capacity, TAOC) and endothelial injury (soluble intracellular adhesion molecule 1, sICAM1) markers to glycemic control measures from 3 days of continuous glucose monitoring (CGM) and to hemoglobin $\mathrm{A}_{1 \mathrm{c}}\left(\mathrm{HbA}_{1 \mathrm{c}}\right)$, and $\mathrm{HbA}_{1 \mathrm{c}} \times$ duration area under the curve (A1cDur).

Results: Seventeen adolescents (8 F/9M; age, $13.1 \pm 1.6$ years (mean $\pm \mathrm{SD}$ ); duration, $4.8 \pm 3.8$ years, BMI, $20.3 \pm 3.1 \mathrm{~kg} / \mathrm{m}^{2}$; A1c, $8.3 \pm 1.2 \%$ ) were studied. Log CRP but was not related to age, duration, body mass index (BMI), $\mathrm{HbA}_{1 \mathrm{c}}$, or A1cDUR. TAOC increased as logA1cDUR increased $(n=13, r=0.61, p=0.028)$. CRP and sICAM were not related to CGM average glucose but log CRP increased as 3 day glucose standard deviation increased $(r=0.66$, $\mathrm{p}=0.006)$. TAOC increased as glucose standard deviation increased $(\mathrm{r}=0.63, \mathrm{p}=0.028)$.

Conclusions: Increased glucose variability is associated with increased inflammation in adolescents withT1D. Increased TAOC with increasing variability may be an effort to compensate for the ongoing oxidative stress.

Keywords: glucose variability; inflammation; oxidation; type 1 diabetes; vascular endothelial injury/stress.

*Corresponding author: Robert P. Hoffman, MD, Department of Pediatrics, The Ohio State University, The Research Institute at Nationwide Children's Hospital, 700 Children's Drive, ED422, Columbus, OH 43205, USA, Phone: +614-722-4425,

Fax:+614-722-4440, E-mail: Robert.hoffman@nationwidechildrens.org Amanda S. Dye: Department of Pediatrics, West Virginia University, Charleston, WV, USA

Hong Huang and John A. Bauer: Department of Pediatrics, University of Kentucky, UK Medical Center MN, Lexington, KY, USA

\section{Introduction}

Cardiovascular disease is the major cause of death for patients with type 1 diabetes (T1D) [1] and there is clear evidence that cardiovascular disease has its origins in childhood and adolescence [2-5]. Inflammation and vascular endothelial injury are early events in nearly all forms of cardiovascular disease and several studies have shown that these biomarkers are also elevated in adolescents with type 1 diabetes prior to the clinical development of cardiovascular complications [6, 7]. Given the increased prevalence of T1D in children and its strong link to early heart disease in adulthood it is critical that we learn more about early predictors of complications and relationships among blood glucose abnormalities and biomarkers of disease processes to enable improved strategies for prevention and/or therapy.

Current clinical management of T1D relies heavily on the average glycemia measure of hemoglobin $\mathrm{A}_{1 \mathrm{c}}\left(\mathrm{HbA}_{1 \mathrm{c}}\right)$, but some very recent reports (mostly in adults) suggest that variations in blood glucose, rather than absolute or timeaveraged values, may be more strongly linked to unfavorable outcomes. Specifically, in type 2 diabetes microvascular complications and coronary artery disease are consistently related to increased glucose variability although these relationship have not been found in adults with T1D [8]. Thus, the significance of increased glucose variability in T1D is controversial $[9,10]$. Pathophysiologically, increased glucose variation may increase oxidative tissue damage more than continuous hyperglycemia [11, 12].

The goal of this study was to determine the relationship of biochemical inflammatory, oxidative, and endothelial markers to fasting glucose, $72 \mathrm{~h}$ mean glucose and glucose variability, $\mathrm{HbA}_{1 \mathrm{c}}$ and $\mathrm{HbA}_{1 \mathrm{c}}$ over time in adolescents with T1D. High sensitivity C-reactive protein (CRP) is the most studied inflammatory marker in pediatric type 1 diabetes. In healthy adults, CRP levels predict future cardiovascular disease and are linked to endothelial dysfunction [13-15], Most [6, 7, 16-22], but not all studies [23, 24], have demonstrated significant increases in CRP levels in pediatric T1D patients. Soluble intracellular adhesion molecule 1 (sICAM 1) is biochemical marker of endothelial damage and inflammation and is again elevated in pediatric T1D [7, 20, 25-27]. 


\section{Materials and methods}

\section{Subjects}

Seventeen adolescents (eight female, nine male) with T1D were recruited from the Pediatric Diabetes Clinic of Nationwide Children's Hospital (NCH). The study was approved by the NCH Institutional Review Board and informed consent was obtained from parent or legal guardian. Proper assent was obtained from all subjects.

Screening included a history, physical exam, Tanner staging, and fasting laboratory testing. T1D was defined by American Diabetes Association criteria plus a fasting C-peptide of $<0.4 \mathrm{ng} / \mathrm{mL}$, insulin monotherapy since diagnosis, and an absence of a history of oral hypoglycemic agents and acanthosis nigricans on exam.

All subjects were Tanner stage 2-4 in order to minimize the effects of starting or finishing puberty. In order to limit confounding effects on endothelial function, subjects with BP $>95 \%$, smoking, pregnancy, and uncorrected hypothyroidism, were excluded. Subjects with microalbuminuria, overt nephropathy, or early renal failure (random urine microalbumin/creatinine $>0.02 \mathrm{mg}$ albumin/ $\mathrm{mg}$ creatinine; serum creatinine $>1.0 \mathrm{mg} / \mathrm{dL}$ ) were, also, excluded.

\section{Protocol}

Subjects were admitted to the Clinical Research Center of the Wexner Medical Center at the Ohio State University at 07:30 after having fasted from 22:00 the night before. Subjects were instructed to take their usual basal insulin the night before or to remain on their usual basal insulin infusion rates if using continuous subcutaneous insulin. Subjects withheld their morning insulin bolus until breakfast was given after the study completion. A blood sample was then collected for measurement of fasting glucose and biochemical markers. Eleven patients then participated in an insulin clamp study to assess the effects of glucose normalization and hyperglycemia. Results on this study have been previously reported [28] as have results on endothelial function [29]. Subjects were then placed on a continuous glucose monitor (CGM, Medtronic Guardian, Fridley, MN, USA) for 3 days after which the CGM was returned and the data downloaded using the Medtronic Carelink website to determine the mean glucose level and standard deviation.

\section{Laboratory measurements}

CRP, total plasma antioxidant capacity (TAOC), a measure of oxidative stress, and sICAM1 were measured. TAOC is a non-specific assay of anti-oxidant defense which measures the ability of constituents in plasma to absorb oxidation (BioVision Research Products, Mountain View, CA, USA). TAOC results were available in only 13 subjects. Serum sICAM levels were determined using a commercially available assay (R \& D Systems, Minneapolis, MN, USA; Cat \# BBE 1B).

\section{Statistical analysis}

Hemoglobin $A_{1 c}$ by duration area under the curve (A1cDur) was calculated using the trapezoidal rule. Pearson's regression analysis was used to assess the relationship between biochemical markers and the various measures of glucose control. Data was log normalized, as needed. All analysis was performed using Systat 13 (Systat Software Inc, Chicago, IL, USA). Results are reported as mean \pm SD.

\section{Results}

\section{Age, duration, BMI effects and blood pressure effect}

Mean demographic, glucose, and laboratory values for the subjects are shown in Table 1. Age and BMI were not significantly related to any of the measures (Table 2). Systolic blood pressure (SBP) but not diastolic pressure (DBP) increased as duration of diabetes increased $(r=0.62$, $\mathrm{p}=0.009$ ). Neither was significantly related to age or BMI. TAOC increased as diabetes duration increased and logCRP tended to do the same. LogCRP increased as systolic blood

Table 1: Demographic and biochemical parameters.
Age, years

Duration, years

BMI, $\mathrm{kg} / \mathrm{m}^{2}$

Systolic pressure, $\mathrm{mmHg}$

Diastolic pressure, $\mathrm{mmHg}$

$\mathrm{HbA}_{1 \mathrm{c}}, \%$

Fasting glucose, $\mathrm{mg} / \mathrm{dL}$

$72 \mathrm{~h}$ mean glucose, $\mathrm{mg} / \mathrm{dL}$

$72 \mathrm{~h}$ glucose standard deviation, $\mathrm{mg} / \mathrm{dL}$

$\mathrm{C}$-reactive protein, $\mathrm{ng} / \mathrm{mL}$

Soluble intracellular adhesion molecule, $\mathrm{ng} / \mathrm{mL}$

Total anti-oxidant capacity, units
$4.8 \pm 3.8$

$20.3 \pm 3.1$

$106 \pm 6$

$61 \pm 9$

$8.3 \pm 1.2$

$160 \pm 67$

$200 \pm 46$

$80 \pm 20$

$1.45 \pm 2.93$

$196 \pm 80$

$130 \pm 40$
$13.1 \pm 1.6$

Table 2: Correlation coefficient relationships of high sensitivity C-reactive protein (hsCRP), total anti-oxidant capacity (TAOC) and soluble intracellular adhesion molecule (sICAM) to age, duration, $\mathrm{BMI}$, and glucose control variables in adolescent type 1 diabetes.

\begin{tabular}{lrrr}
\hline & LoghsCRP & TAOC & LogsICAM \\
\hline Age & 0.03 & 0.23 & -0.36 \\
Duration & $0.42^{\mathrm{a}}$ & $0.61^{\mathrm{b}}$ & 0.24 \\
BMI & 0.34 & 0.22 & -0.3 \\
SBP & $0.49^{\mathrm{a}}$ & 0.08 & 0.44 \\
DBP & 0.18 & -0.02 & 0.35 \\
Fasting glucose & -0.11 & 0.16 & -0.27 \\
Log 72 h mean glucose & 0.15 & 0.39 & 0.24 \\
72 h standard deviation & $0.66^{\mathrm{b}}$ & $0.63^{\mathrm{a}}$ & 0.46 \\
Hemoglobin A & 0.15 & 0.38 & 0.27 \\
LogA1cAUC & 0.39 & $0.61^{\mathrm{a}}$ & 0.42 \\
\hline
\end{tabular}

${ }^{\mathrm{a}} \mathrm{p}<0.05,{ }^{\mathrm{b}} \mathrm{p}<0.01$. 
pressure increased and logsICAM tended to do the same. DBP was not related to hsCRP, TAOC, or SICAM.

\section{Glucose control effects}

SBP increased as logA1cDur increased $(\mathrm{r}=0.63, \mathrm{p}=0.007)$ but was not related to any of the other glycemic control measures. DBP was not related to any of the glycemic control measures. $\mathrm{HbA}_{1 \mathrm{c}}$ increased in older subjects $(\mathrm{r}=0.55, \mathrm{p}=0.021)$.

LogCRP was not related to fasting glucose, $72 \mathrm{~h}$ mean glucose, $\mathrm{HbA}_{1 \mathrm{c}}$ or A1cDur but was significant related to $72 \mathrm{~h}$ glucose standard deviation (Figure 1). TAOC increased as $\log \mathrm{A} 1 \mathrm{cDur}$ increased as glucose standard deviation increased but was not related to the other measures. LogsICAM tended to increase as glucose standard deviation and A1cAUC increased.

\section{Discussion}

Our study is the first to report on the relationship of glucose variability to markers of inflammation, oxidation, and endothelial damage in adolescents with T1D. The results demonstrate that increasing glucose variability is associated with increasing inflammation as indicated by increasing levels of CRP. There was no relationship of inflammation to other measures of short, intermediate, or long-term glycemic control. Surprisingly, increased glucose variability was associated with increased, not decreased, TAOC. This may be compensation for increased oxidative stress. This hypothesis is supported by the positive relationships between TAOC and duration and A1cDur.

Hyperglycemia-induced oxidative stress plays a key role in increasing inflammation $[30,31]$. Animal studies have suggested that intermittent hyperglycemia has a more pronounced effect than sustained hyperglycemia [10, 32, 33], although thus far human studies have been less convincing. We have previously found no relationship between glucose variability and endothelial function or endothelial progenitor cells in adolescents with T1D [29]. In adults with T1D Gordin et al. [34] found no relationship between glucose variability and arterial stiffness and Cesana et al. [35] found no relationship to carotid intimal thickness. No relationship was found between glucose variability and microvascular or macrovascular complications in the Diabetes Control and Complications Trial [36-38]. Prospective studies have yielded variable results. In adults with T1D, Buse et al. [39] used sensor augmented pump therapy to reduce glucose variability in comparison to multiple daily injections and found a decrease in inflammatory ligand CD40L levels in the pump group but an increase in the injection group although the difference was not significant. In a single group study Dal et al. [32] found no effect of flexible insulin therapy designed to reduce glucose variability although mean amplitude glucose excursion also did not change. Jamiolkowska et al. [40] found that reducing glucose variability improved endothelial function in adolescents with T1D.

From our study it is unclear what the long-term effects of increased glucose variability and inflammation in adolescent T1D will be. We found no relationship between glucose variability and blood pressure and subjects with evidence of early diabetes complications were excluded. We did find increased systolic blood pressure in subjects with long-standing poor diabetes control. We studied a small number of subjects so there may be additional relationships that were not detected. This is particularly true regarding SICAM were several of the correlation coefficients suggest possible relationships.
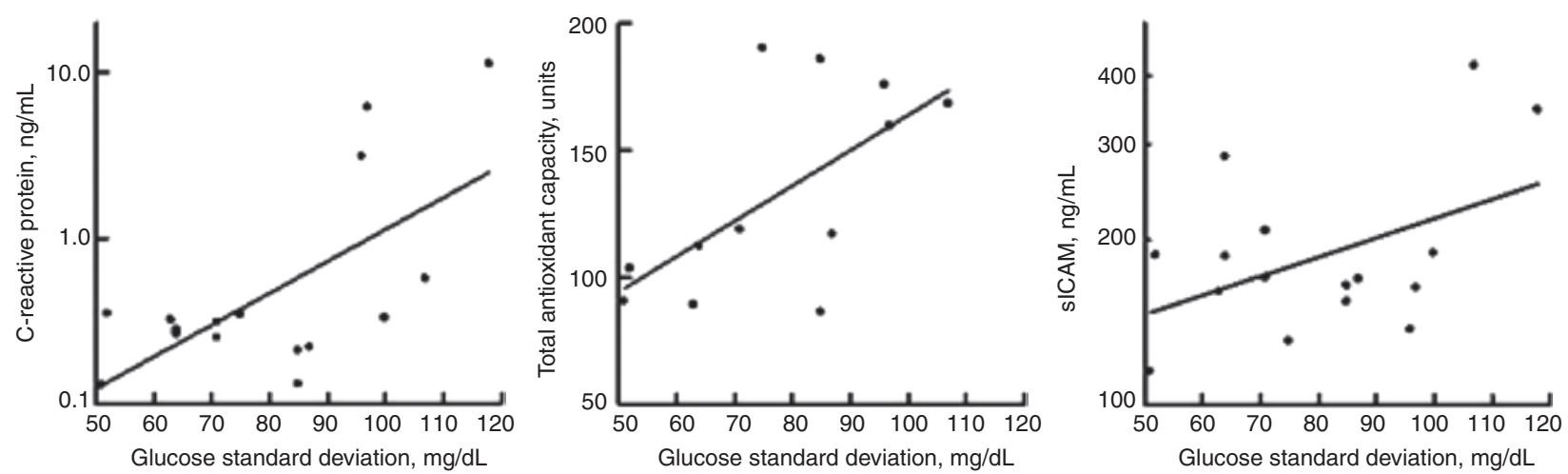

Figure 1: Relationship of $c$-reactive protein $(r=0.63, p=0.006)$, total anti-oxidant capacity $(r=0.63, p=0.028)$ and soluble intracellular adhesion molecule $(r=0.46, p=0.070)$ to $72 \mathrm{~h}$ glucose standard deviation in adolescents with type 1 diabetes. 
In conclusion, increased glucose variability in adolescents with type 1 diabetes is associated with increased inflammation. Future longitudinal studies will be needed to explore the long term effects.

Acknowledgments: The authors thank Karen Carter, Lauren Bird, and Jesse Haines (Research Institute at Nationwide Children's Hospital) for their help with recruiting subjects and performing the research and the nurses of the CRC for their help with the blood drawing.

Author contributions: All the authors have accepted responsibility for the entire content of this submitted manuscript and approved submission. RH wrote protocol and obtained research funding, supervised or directly collected data, wrote and edited the manuscript. He is responsible for its content. AD participated in data collection and reviewed the manuscript. HH performed laboratory measurement and reviewed the manuscript. JB supervised laboratory measurements and reviewed and edited manuscript. Dr. Robert Hoffman is the guarantor of this work and, as such, had full access to all the data in the study and takes responsibility for the integrity of the data and the accuracy of the data analysis.

Research funding: This study was supported by the National Institutes of Health NIDDK grant R21DK08364201 and the American Reinvestment and Recovery Act of 2009. The project described was, also, supported by Award Number UL1RR025755 from the National Center for Research Resources. The content is solely the responsibility of the authors and does not necessarily represent the official views of the National Center for Research Resources or the National Institutes of Health. The authors have no conflicts of interest related to this manuscript.

Employment or leadership: None declared.

Honorarium: None declared.

Competing interests: The funding organization(s) played no role in the study design; in the collection, analysis, and interpretation of data; in the writing of the report; or in the decision to submit the report for publication.

\section{References}

1. Giannini C, Mohn A, Chiarelli F, Kelnar CJ. Macrovascular angiopathy in children and adolescents with type 1 diabetes. Diabetes Metab Res Rev 2011;27:436-60.

2. Enos WF, Holmes RH, Beyer J. Landmark article, July 18, 1953: Coronary disease among United States soldiers killed in action in Korea. Preliminary report. By William F. Enos, Robert H. Holmes and James Beyer. J Am Med Assoc 1986;256:2859-62.
3. McGill HC, Jr., McMahan CA, Herderick EE, Malcom GT, Tracy RE, et al. Origin of atherosclerosis in childhood and adolescence. Am J Clin Nutr 2000;72:1307S-15S.

4. Abd El Dayem SM, El Magd El Bohy A, Battah AA. Carotid intimal medial thickness and its relation to endothelial dysfunction and echocardiographic changes in adolescents with type 1 diabetes. J Pediatr Endocrinol Metab 2015;28:1029-37.

5. dos Santos Alves Pde J, AC PTH, Pinto LR, RM SM, CH MA, Alves RS, FH CC. Endothelial and metabolic disorders in adolescence: low birth weight is not an isolated risk factor. J Pediatr Endocrinol Metab 2015;28:407-13.

6. Snell-Bergeon JK, West NA, Mayer-Davis EJ, Liese AD, Marcovina $\mathrm{SM}$, et al. Inflammatory markers are increased in youth with type 1 diabetes: the SEARCH Case-Control study. J Clin Endocrinol Metab 2010;95:2868-76.

7. Heier M, Margeirsdottir HD, Brunborg C, Hanssen KF, Dahl-Jorgensen K, et al. Inflammation in childhood type 1 diabetes; influence of glycemic control. Atherosclerosis 2015;238:33-7.

8. Smith-Palmer J, Brandle M, Trevisan R, Orsini Federici M, Liabat $\mathrm{S}$, et al. Assessment of the association between glycemic variability and diabetes-related complications in type 1 and type 2 diabetes. Diabetes Res Clin Pract 2014;105:273-84.

9. Bolli GB. Glucose variability and complications. Diabetes Care 2006;29:1707-9.

10. Hirsch IB, Brownlee M. Should minimal blood glucose variability become the gold standard of glycemic control? J Diabetes Complications 2005;19:178-81.

11. Choi S-W, Benzie IF, Ma S-W, Strain JJ, Hannigan BM. Acute hyperglycemia and oxidative stress: direct cause and effect? Free Radic Biol Med 2008;44:1217-31.

12. Monnier L, Mas E, Ginet C, Michel F, Villon L, et al. Activation of oxidative stress by acute glucose fluctuations compared with sustained chronic hyperglycemia in patients with type 2 diabetes. J Am Med Assoc 2006;295:1681-7.

13. Yudkin JS, Stehouwer CD, Emeis JJ, Coppack SW. C-reactive protein in healthy subjects: associations with obesity, insulin resistance, and endothelial dysfunction: a potential role for cytokines originating from adipose tissue? Arterioscler Thromb Vasc Biol 1999;19:972-8.

14. Van Gaal LF, Mertens IL, De Block CE. Mechanisms linking obesity with cardiovascular disease. Nature 2006;444:875-80.

15. Joshi MS, Tong L, Cook AC, Schanbacher BL, Huang H, et al. Increased myocardial prevalence of $\mathrm{C}$-reactive protein in human coronary heart disease: direct effects on microvessel density and endothelial cell survival. Cardiovasc Pathol 2012;21: 428-35.

16. Goksen D, Levent E, Kar S, Ozen S, Darcan S. Serum adiponectin and hsCRP levels and non-invasive radiological methods in the early diagnosis of cardiovascular system complications in children and adolescents with type 1 diabetes mellitus. J Clin Res Pediatr Endocrinol 2013;5:174-81.

17. Lamichhane AP, Liese AD, Urbina EM, Crandell JL, Jaacks LM, et al. Associations of dietary intake patterns identified using reduced rank regression with markers of arterial stiffness among youth with type 1 diabetes. Eur J Clin Nutr 2014;68:1327-33.

18. Truong UT, Maahs DM, Daniels SR. Cardiovascular disease in children and adolescents with diabetes: where are we, and where are we going? Diabetes Technol Ther 2012;14 Suppl 1:S11-21. 
19. Neyestani TR, Ghandchi Z, Eshraghian MR, Kalayi A, Shariatzadeh $\mathrm{N}$, et al. Evidence for augmented oxidative stress in the subjects with type 1 diabetes and their siblings: a possible preventive role for antioxidants. Eur J Clin Nutr 2012;66:1054-8.

20. Heilman K, Zilmer M, Zilmer K, Tillmann V. Lower bone mineral density in children with type 1 diabetes is associated with poor glycemic control and higher serum ICAM-1 and urinary isoprostane levels. J Bone Miner Metab 2009;27:598-604.

21. Babar GS, Zidan H, Widlansky ME, Das E, Hoffmann RG, et al. Impaired endothelial function in preadolescent children with type 1 diabetes. Diabetes Care 2011;34:681-5.

22. Eltayeb AA, Ahmad FA, Sayed DM, Osama AM. Subclinical vascular endothelial dysfunctions and myocardial changes with type 1 diabetes mellitus in children and adolescents. Pediatr Cardiol 2014;35:965-74.

23. Faienza MF, Acquafredda A, Tesse R, Luce V, Ventura A, et al. Risk factors for subclinical atherosclerosis in diabetic and obese children. Int J Med Sci 2013;10:338-43.

24. Davis NL, Bursell JD, Evans WD, Warner JT, Gregory JW. Body composition in children with type 1 diabetes in the first year after diagnosis: relationship to glycaemic control and cardiovascular risk. Arch Dis Child 2012;97:312-5.

25. Maggio AB, Farpour-Lambert NJ, Montecucco F, Pelli G, Marchand LM, et al. Elevated E-selectin and diastolic blood pressure in diabetic children. Eur J Clin Invest 2012;42:303-9.

26. Seckin D, Ilhan N, Ilhan N, Ertugrul S. Glycaemic control, markers of endothelial cell activation and oxidative stress in children with type 1 diabetes mellitus. Diabetes Res Clin Pract 2006;73:191-7.

27. Elhadd TA, Kennedy G, Hill A, McLaren M, Newton RW, et al. Abnormal markers of endothelial cell activation and oxidative stress in children, adolescents and young adults with type 1 diabetes with no clinical vascular disease. Diabetes Metab Res Rev 1999;15:405-11.

28. Dye AS, Huang H, Bauer JA, Hoffman RP. Hyperglycemia increases muscle blood flow and alters endothelial function in adolescents with type 1 diabetes. Exp Diabetes Res 2012;2012:9.

29. Hoffman RP, Dye AS, Huang H, Bauer JA. Effects of glucose control and variability on endothelial function and repair in adolescents with type 1 diabetes. ISRN Endocrinology 2013;2013:7.
30. Cai H, Harrison DG. Endothelial dysfunction in cardiovascular diseases: the role of oxidant stress. Circ Res 2000;87:840-4.

31. Stehouwer CD, Lambert J, Donker AJ, van Hinsbergh VW. Endothelial dysfunction and pathogenesis of diabetic angiopathy. Cardiovasc Res 1997;34:55-68.

32. Dal S, Jeandidier N, Seyfritz E, Bietiger W, Peronet C, et al. Featured article: oxidative stress status and liver tissue defenses in diabetic rats during intensive subcutaneous insulin therapy. Exp Biol Med (Maywood) 2016;241:184-92.

33. Yin X, Zheng F, Pan Q, Zhang S, Yu D, et al. Glucose fluctuation increased hepatocyte apoptosis under lipotoxicity and the involvement of mitochondrial permeability transition opening. J Mol Endocrinol 2015;55:169-81.

34. Gordin D, Ronnback M, Forsblom C, Makinen V, Saraheimo M, Groop PH. Glucose variability, blood pressure and arterial stiffness in type 1 diabetes. Diabetes Res Clin Pract 2008;80:e4-7.

35. Cesana F, Giannattasio C, Nava S, Soriano F, Brambilla G, et al. Impact of blood glucose variability on carotid artery intima media thickness and distensibility in type 1 diabetes mellitus. Blood Press 2013;22:355-61.

36. Kilpatrick ES, Rigby AS, Atkin SL. The effect of glucose variability on the risk of microvascular complications in type 1 diabetes. Diabetes Care 2006;29:1486-90.

37. Kilpatrick ES, Rigby AS, Atkin SL. Mean blood glucose compared with $\mathrm{HbA1C}$ in the prediction of cardiovascular disease in patients with type 1 diabetes. Diabetologia 2008;51:365-71.

38. Kilpatrick ES, Rigby AS, Atkin SL. Effect of glucose variability on the long-term risk of microvascular complications in type 1 diabetes. Diabetes Care 2009;32:1901-3.

39. Buse JB, Kudva YC, Battelino T, Davis SN, Shin J, et al. Effects of sensor-augmented pump therapy on glycemic variability in wellcontrolled type 1 diabetes in the STAR 3 study. Diabetes Technol Ther 2012;14:644-7.

40. Jamiolkowska M, Jamiolkowska I, Luczynski W, Tolwinska J, Bossowski A, et al. Impact of real-time continuous glucose monitoring use on glucose variability and endothelial function in adolescents with type 1 diabetes: new technology-new possibility to decrease cardiovascular risk? J Diabetes Res 2016;2016:4385312. 